\title{
A REVIEW OF THE SPECIES OF GENUS ISOTIMA FOERSTER (HYMENOPTERA: ICHNEUMONIDAE) FROM KERALA ALONG WITH THE DESCRIPTION OF TWO NEW SPECIES
}

\author{
K. Sudheer ${ }^{1}$ and T.C. Narendran ${ }^{2}$
}

Systematic Entomology Laboratory, Department of Zoology, University of Calicut, Kerala 673635, India

Email: 'sudheer_kt03@yahoo.co.in; '2drtcnarendran@yahoo.com

\begin{abstract}
The species of the Ichneumonid genus Isotima Foerster occurring in Kerala is reviewed. Two new species viz., I. anupama sp. nov. and I. rakela sp. nov. are illustrated and described. Their affinities with their closest relatives are discussed. I. rufithorax (Szepligeti) is newly recorded from Kerala. The larvae of Hyblaea puera (Cramer) is a new host record for I. pusilla (Szepligeti). A key to the Oriental species of Isotima Foerster is also provided.
\end{abstract}

\section{KeYWORDS}

Hymenoptera, Ichneumonidae, India, Isotima, I. anupama, I. bicarinata, I. kamathi, I. pusilla, I. rakela, I. rufipleuralis, I. rufithorax, Kerala, new species

\section{Abbreviations}

BUDAPEST - Termeszettudomanyi Muzeum Allatara (Zoological Department of the Hungarian Natural History Museum), Budapest, Hungary; DZUC - Department of Zoology, University of Calicut; EBERSWALDE - Institut für Pflanzenschutzforschung Kleinmachnow, Abt. Taxonomie der Insekten, DDR Germany; F - Female; FLORIDA - Collections of Prof. Virendra K. Gupta, Located at the American Entomological Institute, Gainesville, Florida, U.S.A.; FWL - Fore wing length; FWW - Fore wing width; HW - Head width; HL - Head length; HWL - Hind wing length; HWW - Hind wing width; M - Male; ZSIK - Western Ghats Regional Station of the Zoological Survey of India, Kozhikode.

The largest family of the Order Hymenoptera is the Family Ichneumonidae, with approximately 60,000 species (Townes, 1969; Yu, 2002). The genus Isotima Foerster, which belongs to Subfamily Cryptinae of Ichneumonidae, is widely distributed in the Oriental Region (Wahl, 1999). Foerster, (1868) erected the genus Isotima with I. albicineta Ashmead as its type species. Townes et al. (1961) synonymized several genera like Formostenus Uchida, Gambroides Betrem and Fotsiforia Seyrig and also catalogued 14 species under the genus. Jonathan (1980) studied the species of Isotima-complex and described 12 new species of the genus from Oriental Region and also restored the status of the genera like Formostenus Uchida, Gambroides Betrem and Fotsiforia Seyrig synonymized by Townes under Isotima. Jonathan (1982) later reported a new species, I. andamanensis from Andaman Islands. Gupta (1987) catalogued 21 valid species, of which 17 have been reported from India. Kanhekar (1989) recorded two new species, I. dorsalis and I. aurangabadensis, and, Sathe and Dawale (2002) reported a new species, I. orientalis from Maharashtra, India. The genus Isotima Foerster is now represented by 24 species in the Oriental Region. In this paper, the species of Isotima Foerster occurring in the state of Kerala is reviewed. The present investigation recognizes seven species, of which two are new to science. I. rufithorax (Szepligeti) is recorded for the first time from Kerala. A key to the Oriental species of Isotima Foerster is also provided. Most of the members were found among bushes, while I. pusilla (Szepligeti) was reared from Hyblaea puera (Cramer). The type materials of the newly described taxa are deposited in the TCN Collections of the Systematic Entomology Laboratory, Department of Zoology, University of Calicut (DZCU) for the time being but eventually will be transferred to the Western Ghats Regional Station of the Zoological Survey of India, Kozhikode, Kerala (ZSIK).

\section{Genus Isotima Foerster}

Isotima Foerster, 1868a. Verh. Naturh. Ver. Rheinlande, 25: 182. Type: Isotima albicineta Ashmead. Designated by Townes, $1957 \mathrm{~b}$.

Diagnosis: Head moderately large; clypeus of moderate size, slightly convex, apical margin impressed, moderately arched apex; frons usually with a weak median longitudinal groove or carina, also with a semicircular carina above each antennal socket that encloses a shallow basin, carina often developed into flanges or horns in males; mandible of moderate size, upper tooth slightly longer; epomia short, never reaching upper margin of pronotum; notaulus sharp and distinct, extending beyond middle of mesoscutum; lateral carina of scutellum extending beyond $0.5 \mathrm{x}$ its height; sternaulus extending to base of mid coxa; propodeum with both transverse carina, basal carina strong and complete, apical carina complete or obsolescent in middle, with weak or moderate sublateral crests; areolet usually square to somewhat pentagonal, second intercubitus faint, second recurrent vein vertical or subvertical; nervulus usually opposite but may be little distad or basad of basal vein, nervellus usually intercepted at or below middle; first abdominal tergite short and stout, with a lateral tooth at base, its spiracles close to apex than to each other, tergite at base usually quadrate in cross-section, its dorso-median, dorso-lateral and ventro-lateral carinae present, usually sharp, dorso-median carina reaching to or beyond spiracle, dorso-lateral and ventro-lateral carina complete, sometimes ventrolateral carina weak, edge rounded; ovipositor tip moderately short, with distinct nodus and usually with distinct teeth on lower valve.

Distribution: Oriental Region.

Discussion: Isotima Foerster closely resembles Formostenus Uchida in having frons with a semicircular carina above each antennal socket, epomia and sternaulus distinct and prepectal 
carina long, extending up to base of subtegular ridge. However the genus Isotima Foerster can be distinguished from Formostenus Uchida in having first abdominal segment short and thick in shape, its spiracles close to apex than to each other and ovipositor long, blunt, never curved.

\section{Isotima anupama sp. nov.}

(Figs. 1-5)

\section{Material examined}

Holotype: 1F, 18.ix.2002, Calicut University Campus (75051'E$\left.11^{0} 7^{\prime} \mathrm{N}\right)$, Malappuram, Kerala, India, P. Girishkumar (Reg. No. SK 203).

\section{Etymology}

The species name is from Sanskrit, which means 'unique', due to its unique features in wing venation.

\section{Female}

Body length (excluding ovipositor) - 8.03mm. Body covered with fine, short, golden yellow hairs; hairs sparsely distributed on propodeum and first abdominal tergite.

Head: In dorsal view (Fig. 3) HW - 1.9mm and HL - 0.58mm; HW - 1.9mm and HL - 1.5mm in front view (Fig. 2); face thickly and closely punctate; clypeus with distinct punctures, interstices smooth and shiny, apex impressed, smooth and shiny, slightly convex; malar space granulose, $0.5 \mathrm{x}$ basal width of mandible; mandible with shallow punctures, smooth at apex, lower tooth slightly smaller than upper tooth; antennal scrobe deep, smooth; interocellar distance (Fig. 3) 0.6x ocellocular distance, $1 \mathrm{x}$ distance between median and lateral ocelli; frons rugose in middle, smooth at sides, a groove extending from median ocellus to middle of semicircular carina; semicircular carina above each antennal scrobe projecting like a flange; vertex and temple with close, minute punctures; antenna (Fig. 1) with 29 segments; scape $1 \mathrm{x}$ as long as pedicel, $1 \mathrm{x}$ as long as its width; pedicel $0.42 \mathrm{x}$ as long as first flagellar segment; first flagellar segment $6 \mathrm{x}$ as long as its width at apex, 1.0x as long as second flagellar segment, $3 \mathrm{x}$ as long as last flagellar segment; second flagellar segment $1.1 \mathrm{x}$ as long as third flagellar segment.

Thorax: $4.95 \mathrm{x}$ as long as head length in dorsal view, $2.36 \mathrm{x}$ as long as width between tegulae; pronotum with close, minute punctures on upper and lower margin, trans-striate in middle; epomia distinct, short, not extending to upper margin; mesoscutum minutely and closely punctate; notaulus sharp, distinct, extending beyond middle of mesoscutum; scutellum and metascutellum largely smooth and shiny, with distinct, shallow punctures; lateral carina of scutellum extending whole length of scutellum; propodeum (Fig. 4) largely reticulate, basal and apical carina complete, low crest like apophyses present, area basad of basal carina largely smooth, with scattered, shallow punctures, basal stumps of longitudinal carina present; mesopleurum with deep punctures, punctures running into rugosities, speculum smooth and shiny; prepectal carina extending $0.6 \mathrm{x}$ height of mesopleurum; metapleurum rugose, juxtacoxal carina present; FWL - 5.44mm; FWW - 1.83 mm; HWL

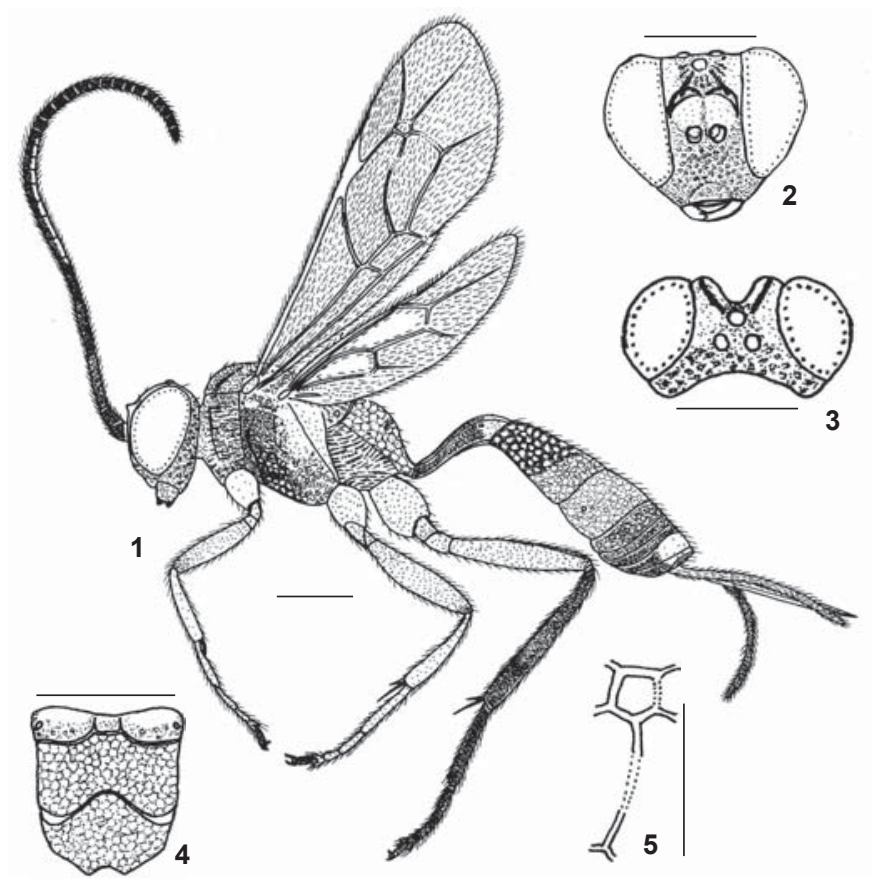

Figures 1-5. Isotima anupama sp. nov. (Female) 1 - Body profile; 2 - Head-Front view; 3 - Head-Dorsal view; 4 - Propodeum; 5 - Areolet. Scale $=1 \mathrm{~mm}$

- 3.67mm; HWW - 0.94mm; areolet (Fig. 5) pentagonal, 0.82x as high as length of second recurrent vein above bulla, $6 \mathrm{x}$ as high as width of bordering veins; nervulus distinctly apicad (Fig. 1) of basal vein; nervellus intercepted at about $0.43 \mathrm{x}$ distinctly below middle; hind wing with one basal and six apical hamuli.

Abdomen: First tergite largely smooth and shiny, with minute punctures at apex, $1.5 \mathrm{x}$ as long as its width at apex, $1 \mathrm{x}$ as long as length of second abdominal tergite, median dorsal longitudinal carina strong; second and third tergites with close, deep punctures; thyridium distinct; fourth and remaining tergites with closely arranged shallow punctures; long, pointed ovipositor; lower valve of ovipositor with teeth, length of ovipositor - $2.3 \mathrm{~mm}$; ovipositor sheath $1.1 \mathrm{x}$ as long as length of hind tibia.

Colour: Black except following markings: orbital stripes and semicircular carina, pronotal collar, tegula, base of fore wing, fore coxa and fore trochanters, lateral carina of scutellum, apical band on first and second abdominal tergites, seventh and eighth broadly in middle yellow; fourth to ninth flagellar segments and tenth incompletely dorsally white; posterior half of mesopleurum, metapleurum, scutellum, metascutellum, propodeum, first abdominal tergite except apical band, mid and hind coxae and femora of all legs reddish-orange; mid and hind trochanters, tibiae and first four tarsal segments of fore and mid leg yellowish-brown; fifth tarsal segment of legs, hind tibia, hind tarsal segments, claws, wing veins, ovipositor sheath and flagellar segments except dorsal band dark brown; ovipositor reddish-brown; wings clear hyaline. 
Male: Unknown.

Host: Unknown.

Biology: Unknown.

\section{Discussion}

Isotima anupama sp. nov. closely resembles $I$. bicarinata Jonathan in having: (i) a highly specialized semicircular carina, projecting like a flange in female; (ii) frons along eye margin and its semicircular carina marked yellow; and (iii) lateral carina of scutellum marked yellow. However I. anupama sp. nov. can be distinguished from I. bicarinata Jonathan in the following characters: (i) Nervulus distinctly apicad of basal vein in $I$. anupama sp. nov. (In I. bicarinata nervulus opposite basal vein); (ii) In I. anupama sp. nov. nervellus intercepted distinctly below middle (Nervellus intercepted at middle in I. bicarinata); (iii) In I. anupama sp. nov. lateral carina of scutellum extending its whole length (In I. bicarinata lateral carina of scutellum extending to its basal 0.65); and (iv) In I. anupama sp. nov. mesopleurum with deep punctures, punctures running into rugosities (In I. bicarinata mesopleurum weakly to strongly rugose).

\section{Isotima bicarinata Jonathan}

Isotima bicarinata Jonathan, 1980. Rec. Zool. Surv. India. Misc. Publ. Occ. Pap. 17: 38. F, M, key, des., fig., Type: F, India: Tamil Nadu: Palani (FLORIDA).

\section{Diagnosis \\ Female}

Face thickly punctate, punctures in middle tending to be rugosopunctate; clypeus with apical margin wavy, notched in middle; frons with semicircular carina high like a flange; mesopleurum weakly to strongly rugose, finely rugoso-punctate below subtegular ridge and below sternaulus, speculum shiny with scattered minute punctures; metapleurum irregularly transstriate; propodeum largely wrinkled, at places tending to be reticulate, area basad of basal carina closely punctate, with large and oval spiracle, both basal and apical carinae arched in middle, apophyses crest-like; nervellus intercepted at middle.

Colour: Black. Antenna with fourth to ninth flagellar segments white above; semicircular carina and orbital stripes on frons, pronotal collar except below, tegula, subtegular ridge, base of lateral carina of scutellum, apical bands of first and second abdominal tergites, seventh and eighth tergites broadly in middle, fore coxa and trochanter yellow; posterior half of mesopleurum (variable), scutellum, metascutellum, propodeum and base of first abdominal tergite red; fore and mid femora light brown to brown, hind femur yellowish-brown with a blackish mark at apex; tibiae brown except below in middle paler; tarsal segments blackish-brown; wing light brownish-hyaline.

\section{Male}

Similar to female except following: more smooth and polished; mesopleurum with coarse, sparse punctures; metapleurum coarsely punctate; propodeum largely reticulo-punctate.
Colour: Black. Antennal flagellum without a band; head except vertex and mandible at apex, pronotal collar broadly and upper margin of pronotum, tegula, subtegular ridge, scutellum and lateral carina, metascutellum, apical bands of first to fifth abdominal tergites, sometimes sixth faintly, seventh and eighth broadly in middle yellow; rest of thorax (except mesoscutum black) and base of first abdominal tergite dark orange; colour of legs similar to female.

Host: Unknown.

Biology: Unknown.

Distribution: Kerala and Tamil Nadu.

Remarks: This species is not represented in the present collection. This species was reported from Walayar forests in Palghat district of Kerala state by Jonathan (1980). The diagnosis is based on the original description by Jonathan (1980).

\section{Isotima kamathi Jonathan}

Isotima kamathi Jonathan, 1980. Rec. Zool. Surv. India. Misc. Publ. Occ. Pap. 17: 43. F, key, des., Fig. Type: F, India: Kerala; Walayar forest (FLORIDA).

\section{Material examined}

1F, 16.v.2001, Koyilandy ( $\left.75^{\circ} 41^{\prime} E-11^{\circ} 26 ' N\right)$, Kozhikode, Kerala, K.M. Sheema (Reg. No. SK 158); 1F, 24.ix.2001, Calicut University Campus (75051'E-1 $\left.1^{0} 7^{\prime} \mathrm{N}\right)$, Malappuram, Kerala, K. Sudheer (Reg. No. SK 171); 1F, 1.x.2001, Calicut University Campus (75 $51^{\prime} \mathrm{E}-$ $\left.11^{0} 7^{\prime} \mathrm{N}\right)$, Malappuram, Kerala, T. Divakaran (Reg. No. SK 174);

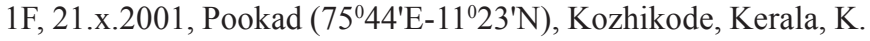
Sudheer (Reg. No. SK 180); 1F, 31.xii.2001, Pookad (75044'E$11^{0} 23^{\prime}$ N), Kozhikode, Kerala, K. Sudheer (Reg. No. SK 186); 1F, 5.v.2002, Pookad (75 $\left.44^{\prime} E-11^{0} 23^{\prime} N\right)$, Kozhikode, Kerala, K. Sudheer (Reg. No. SK 196); 1F, 30.i.2003, Ganapathikallu (76015'E$\left.11^{0} 18^{\prime} \mathrm{N}\right)$, Nilambur forests, Malappuram, Kerala, K. Sudheer (Reg. No. SK 349).

\section{Diagnosis \\ Female}

Face rugoso-punctate in middle, punctate at sides; clypeus with apical margin impressed, somewhat weakly notched in middle; frons with semicircular carina above each antennal sockets moderately broad and high like flange; mesopleurum weakly rugose, near subtegular ridge rugulose, striate below speculum, speculum with indistinct, minute punctures, area just below sternulus somewhat rugoso-punctate, further below subpolished and with indistinct, minute, sparse punctures; juxtacoxal carina present; propodeum between basal carina and apex finely wrinkled, below apophyses trans-wrinkled, basad of basal carina with distinct, sparse punctures, interstices smooth and shiny, spiracles moderately large and oval, apical and basal carinae complete, evenly arched in middle, apophyses crest-like; nervulus opposite basal vein; nervellus intercepted below middle; ovipositor sheath $0.95 \mathrm{x}$ as long as length of hind tibia. 
Colour: Black except following markings: antenna with fourth to eleventh flagellar segments white above; semicircular carina on frons completely, two lateral stripes extending from level of median ocellus and joining mark of semicircular carina, pronotal collar except below, apical bands of first and second abdominal tergites, third tergite with an irregular apical band and seventh and eighth tergites broadly in middle yellow; subtegular ridge, tegula, pronotum along its posterior margin with a triangular black mark, prepectus above, mesopleurum, metapleurum, propodeum, first abdominal tergite at base, fore femur, fore tibia, mid coxa, mid trochanters, mid femur, hind coxa, hind trochanters except two small spots and hind femur orange to deep orange; all tarsal segments except fifth segments, mid tibia, and hind tibia yellowish-brown; wing veins, fifth tarsal segments and claws of all legs, flagellar segments except dorsal band and ovipositor sheath dark brown; wings clear hyaline.

Male: Unknown.

Host: Unknown.

Biology: Unknown.

Distribution: Karnataka and Kerala.

\section{Isotima pusilla (Szepligeti)}

Neomesostenus pusillus Szepligeti, 1916. Ann. Mus. Natl. Hungarici, 14: 294. F. key, des. Type: F, India: Maharashtra: Bombay (BUDAPEST).

Neomesostenus minutus Szepligeti, 1916. Ann. Mus. Natl. Hungarici, 14: 294. M. key, des. Type M, India: Maharashtra: Matheran (BUDAPEST) Syn. by Townes, Townes \& Gupta, 1961.

Neomesostenus persimilis Szepligeti, 1916. Ann. Mus. Natl. Hungarici, 14: 294. M. key, des. Lectotype (designated by Townes, Townes \& Gupta, 1961): M, India: Maharashtra: Bombay (BUDAPEST). Syn. by Jonathan, 1980.

Isotima persimilis: n. comb. by Townes, Townes \& Gupta, 1961. Mem. Amer. Ent. Inst., 1: 145. Lectotype design., India. Syn. by Jonathan, 1980.

Isotima pusilla: n. comb. by Townes, Townes \& Gupta, 1961. Mem. Amer. Ent. Inst., 1: 145. Syn. India.

\section{Material examined}

$1 \mathrm{~F}$ ex. larvae of Hyblaea puera (Cramer), 1.ix.1989, Thrissur $\left(76^{0} 13^{\prime} \mathrm{E}-10^{0} 31^{\prime} \mathrm{N}\right)$, Kerala, K. Mohandas (Reg. No. SK 32); 1M, 21.i.2000, Calicut University Campus (75051'E-1107'N), Malappuram, Kerala, Sojan Abraham (Reg.No. SK 69); 1M, 25.iv.2001, Calicut University Campus (75051'E-1107'N), Malappuram, Kerala, K. Sudheer (Reg. No. SK 155).

\section{Diagnosis}

\section{Female}

Face coarsely punctate, rugoso-punctate in middle; clypeus with apical margin sinuate; frons with semicircular carina not projecting as a flange; mesopleurum largely rugose, trans-striate above mid coxa and mesopleural suture, area below sternaulus with close, minute punctures, propodeum largely reticulate, area basad of basal carina largely smooth and shiny, with minute, sparse punctures, basal and apical carinae complete and evenly arched in middle; nervulus opposite basal vein; nervellus intercepted below middle; ovipositor sheath $1.37 \mathrm{x}$ as long as length of hind tibia.

Colour: Black except following markings: apical band on second abdominal tergite, seventh and eighth tergites broadly in middle and pedicel and scape above yellow; posterior portion of mesopleurum, metapleurum, scutellum, metascutellum, propodeum and first abdominal segment orange to red; fore and mid leg except fifth tarsal segments and claws yellowishbrown; fifth tarsal segments, hind tibia, hind tarsal segments and wing veins brown; hind coxa, hind femur and ovipositor bright red; wings with a brownish tinge.

\section{Male}

Similar to female in their sculpture but show great degree of differences in their colour. Frons moderately strongly rugosopunctate, semicircular carina high, flange-like; mesopleurum weakly rugose with moderately deep punctures.

Colour: Antennal scape, clypeus, mandible except tip, frons along eye margin including semicircular carina, temple in its lower 0.75 , pronotal collar, apical bands of all abdominal tergites (sometimes fifth, sixth and eighth tergites completely black), fore coxae, mid coxae and fore trochanters yellow; rest of thorax and legs largely deep orange; mid tarsal segments, hind trochanter with two small spots, its femur at extreme apex, hind tibia narrowly at base and largely towards apex and all hind tarsal segments dark brown.

Variation: Some females show slight colour variations with the descriptions of I. pusilla (Szepligeti) by Jonathan (1980). Tegula and subtegular ridge, fore coxa and fore trochanters orange instead of yellow.

Host: Eutectona machaeralis (Walker) [Lepidoptera: Pyralidae] (Jonathan, 1980); Hyblaea puera (Cramer) [Lepidoptera: Hyblaeidae].

Biology: Unknown.

Distribution: India [Assam, Bihar, Delhi, Karnataka, Kerala, Rajasthan, Tamil Nadu, Uttar Pradesh]; Myanmar.

Remarks: The species, I. pusilla (Szepligeti) is recorded for the first time as parasitic on the larvae of Hyblaea puera (Cramer).

\section{Material examined}

Isotima rakela sp. nov. (Figs. 6-10)

Holotype: 1F, 31.viii.2002, Calicut University Campus (75051'E$\left.11^{0} 7^{\prime} \mathrm{N}\right)$, Malappuram, Kerala, P. Girish Kumar (Reg. No. SK 197). Paratypes: 1F, 18.vii.2001, Calicut University Campus (75 $51^{\prime} \mathrm{E}-$ $\left.11^{0} 7^{\prime} \mathrm{N}\right)$, Malappuram, Kerala, K. Sudheer, (Reg. No. SK 165); 1F, 18.ix.2001, Calicut University Campus (75051'E-11 $\left.{ }^{0} 7^{\prime} \mathrm{N}\right)$, 
Malappuram, Kerala, K. Sudheer, (Reg. No. SK 168); 1F, 25.ix.2001, Calicut University Campus $\left(75^{\circ} 51^{\prime} \mathrm{E}-11^{0} 7^{\prime} \mathrm{N}\right)$, Malappuram, Kerala, K. Sudheer, (Reg. No. SK 172); 1F, 31.xii.2002, Villooniyal (near Calicut University Campus) (75 $51^{\prime} \mathrm{E}-$ $\left.11^{0} 7^{\prime} \mathrm{N}\right)$, Malappuram, Kerala, P. Girish Kumar (Reg. No. SK 221).

Etymology: The species epithet is an anagram of Kerala, the state from where the type specimen is collected.

\section{Female}

Body length (excluding ovipositor) $=8.8 \mathrm{~mm}$. Body covered with fine, closely arranged golden hairs, hairs sparser on propodeum and first abdominal tergite.

Head: In dorsal view (Fig. 8) HW - 2mm and HL - 0.64mm; HW - $2 \mathrm{~mm}$ and HL - 1.6mm in front view (Fig. 7); face subpolished, distinctly punctate, punctures in middle tending to be rugosopunctate; clypeus distinctly punctate, apex smooth and shiny, apical margin impressed, truncate; malar space (Fig. 6) granulose, $0.45 \mathrm{x}$ basal width of mandible; mandible moderately broad, strongly rugoso-punctate, teeth subequal, lower tooth slightly shorter than upper tooth; frons strongly rugose in middle, distinctly punctate at sides, a groove extending down from base of median ocellus to middle of semicircular carina; semicircular carina behind each antennal scrobe projecting like a flange; vertex with close, shallow punctures; temple distinctly punctate; interocellar distance $0.57 \mathrm{x}$ ocellocular distance, $1.3 \mathrm{x}$ distance between lateral and median ocelli; antenna with 29 segments; scape $1.3 \mathrm{x}$ as long as pedicel, $1.5 \mathrm{x}$ as long as its width; pedicel $0.36 \mathrm{x}$ as long as first flagellar segment; first flagellar segment $6.25 \mathrm{x}$ as long as its width at apex, $1 \mathrm{x}$ as long as second flagellar segment, 3.6x as long as last flagellar segment; second flagellar segment $1.04 \mathrm{x}$ as long as third flagellar segment.

Thorax: 4.4x as long as head length in dorsal view, 1.82x as long as width between tegulae; pronotum with close, minute punctures on upper and lower margin, trans-striate in middle; epomia distinctly short, not reaching upper margin; mesoscutum minutely and closely punctate; notaulus sharp, distinct, extending beyond middle of mesoscutum; scutellum and metascutellum largely smooth and shiny, with distinct, shallow punctures; lateral carina of scutellum extending almost whole length of scutellum; mesopleurum strongly rugose, speculum smooth and shiny, with minute, indistinct punctures; prepectal carina extending $0.7 x$ height of mesopleurum; metapleurum rugose, juxtacoxal carina present; propodeum (Fig. 9) largely reticulate, basal carina complete, slightly arched in middle, apical carina distinct and complete, arched in middle, apophyses crestlike, area basad of basal carina largely smooth and shiny, with scattered, shallow punctures, basal stumps of longitudinal carina present; FWL - 5.6mm; FWW - 2.1mm; HWL - 4mm; HWW - 1mm; areolet (Fig. 10) pentagonal, 0.93x as high as length of second recurrent vein above bulla, $5 \mathrm{x}$ as high as width of bordering veins; nervulus distinctly opposite (Fig. 6) basal vein; nervellus intercepted distinctly below middle; hind wing with one basal and seven apical hamuli.

Abdomen: First tergite largely smooth and shiny, with distinct,

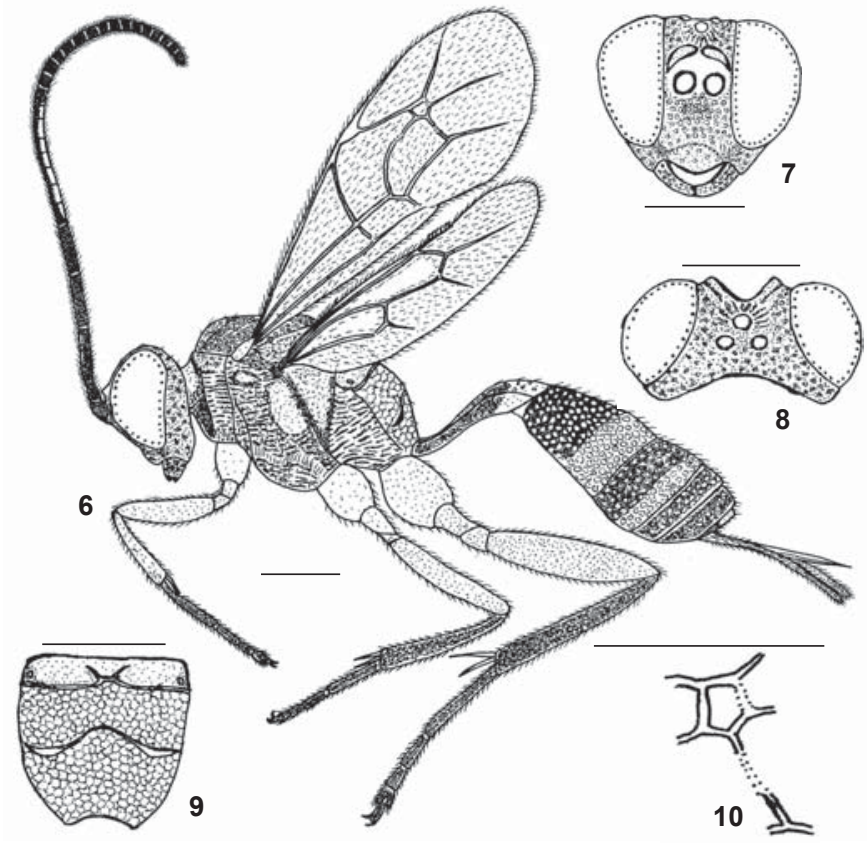

Figures 6-10. Isotima rakela sp. nov. (Female) 6 - Body profile; 7 - Head-Front view; 8 - Head-Dorsal view; 9 - Propodeum; 10 - Areolet. Scale $=1 \mathrm{~mm}$

fine punctures at apex, $1.41 \mathrm{x}$ as long as its width at apex, $1.2 \mathrm{x}$ as long as length of second tergite, median dorsal longitudinal carina strong; second and third tergites with close, deep punctures; distinct thyridium on second tergite; fourth and remaining tergites with closely arranged shallow punctures; ovipositor long, pointed; length of ovipositor - $2.2 \mathrm{~mm}$; ovipositor sheath $0.85 \mathrm{x}$ as long as length of hind tibia.

Colour: Black except following markings: semicircular carina, pronotal collar, tegula, subtegular ridge, fore coxa, fore trochanters, apical bands on first, second and third abdominal tergites, sixth to eighth tergites broadly in middle and labial palps yellow; mesopleurum except near and below sternaulus, scutellum, metascutellum, propodeum, metapleurum, mid and hind coxae, mid and hind trochanters, femora of all legs and fore tibia reddish orange; mid and hind tibiae and tarsal segments of all legs pale brown; fifth tarsal segments of all legs, ovipositor sheath, wing veins and antenna except dorsal band dark brown; flagellar segments fourth to tenth dorsally white; ovipositor red; wings clear hyaline.

Variation: Colour of first abdominal tergite variable: some paratypes with base reddish-orange and apical yellow band with a black spot in middle just anterior to apical band; malar space about $0.5 \mathrm{x}$ basal width of mandible in some paratypes.

Male: Unknown.

Host: Unknown.

Biology: Unknown. 


\section{Discussion}

I. rakela sp. nov. is similar to I. bicarinata Jonathan in having (1) semicircular carina behind each antennal scrobe highly specialized in female, projecting like a flange; (ii) frons along eye margin and its semicircular carina marked yellow; (iii) lateral carina of scutellum marked yellow; and (iv) malar space about $0.44 \mathrm{x}$ basal width of mandible. However, this new species differs from I. bicarinata Jonathan in the following characteristics: (i) In $I$. rakela sp. nov. nervellus intercepted distinctly below middle (Nervellus intercepted at middle in I. bicarinata); (ii) Lateral carina of scutellum extending almost to apex in I. rakela sp. nov. (In I. bicarinata lateral carina of scutellum extending to its basal 0.65 ); (iii) In $I$. rakela $\mathrm{sp}$. nov. apical margin of clypeus slightly truncate, not notched in middle (In I. bicarinata apical margin of clypeus notched in middle); and (iv) Third abdominal tergite with a faint yellow apical band in I. rakela sp. nov. (Third abdominal tergite completely black in I. bicarinata).

I. rakela sp. nov. is also similar to I. rufipleuralis Jonathan in having: (i) nervellus intercepted distinctly below middle; (ii) semicircular carina of frons highly specialized in females; and (iii) frons along eye margin and its semicircular carina marked yellow. However this new species differs from I. rufipleuralis Jonathan in following features: (i) In I. rakela sp. nov. areolet $0.93 \mathrm{x}$ as high as portion of second recurrent vein above bulla (In I. rufipleuralis areolet $0.85 \mathrm{x}$ as high as portion of second recurrent vein above bulla); (ii) Lateral carina of scutellum extending almost to its apex in $I$. rakela sp. nov. (In $I$. rufipleuralis lateral carina of scutellum extending to its basal $0.5)$; (iii) In I. rakela sp. nov. malar space $0.45-0.5 \mathrm{x}$ basal width of mandible (Malar space $0.55 \mathrm{x}$ basal width of mandible in $I$. rufipleuralis); (iv) Apical band on third abdominal tergite faintly and sixth abdominal tergite broadly in middle yellow in I. rakela sp. nov. (In I. rufipleuralis third and sixth abdominal tergites completely black); and (v) Femora of all legs orange in I. rakela sp. nov. (Fore and mid femora brown, hind femur dark orange tending to be brownish-orange towards base in I. rufipleuralis).

Isotima rakela sp. nov. is similar to I. anupama sp. nov. in the following characteristics: (i) nervellus intercepted distinctly below middle; and (ii) lateral carina of scutellum extending whole length of scutellum. However, I. rakela sp. nov. differs from $I$. anupama sp. nov. in the following features: (i) In I. rakela sp. nov. nervulus opposite basal vein (In I. anupama sp. nov. nervulus distinctly apicad of basal vein); (ii) In I. rakela sp. nov. hind wing with seven apical hamuli (Hind wing with six apical hamuli in I. anupama sp. nov.); and (iii) In I. rakela sp. nov. mesopleurum strongly rugose (In I. anupama sp. nov. mesopleurum with deep punctures, punctures running into rugosities).

Isotima rufipleuralis Jonathan

Isotima rufipleuralis Jonathan, 1980. Rec. Zool. Surv. India. Misc. Publ. Occ. Pap. 17: 40. F, key, des., fig. Type: F, India: Karnataka: Bhagmandla, 853m (FLORIDA).

\section{Material examined}

1F, 8.ii.2003, Pookodu lake side $\left(76^{0} 6^{\prime} \mathrm{E}-11^{0} 36^{\prime} \mathrm{N}\right)$, Wayanad,
Kerala, P. Girish Kumar (Reg. No. SK 356).

\section{Diagnosis \\ Female}

Face rugoso-punctate in middle, distinctly punctate at sides; clypeus with apical margin impressed, wavy, slightly notched in middle; semicircular carina broad and high, like a flange; mesopleurum strongly rugose, with weak punctures in middle, posterio-ventral part just below speculum trans-rugose, below sternaulus subpolished and minutely punctate; propodeum with area between basal carina and apex irregularly wrinkled, transwrinkled below apophyses, basad of basal carina strongly punctate except extreme base smooth, punctures near basal carina running into striations, spiracle large and oval, apical carina complete, evenly arched, crest-like apophyses, basal carina complete, slightly dipped in middle; nervulus opposite basal vein; nervellus intercepted below middle; ovipositor sheath about $1.0 \mathrm{x}$ as long as hind tibia.

Colour: Black except following markings: fourth to ninth flagellar segments white above; scape, pedicel and base of first flagellar segment yellowish-brown; flagellar segments blackish-brown; semicircular carina, tegula, subtegular ridge, apical bands on first and second abdominal tergites, seventh and eighth tergites broadly in middle, fore coxa and fore trochanters yellow; mid coxa and mid trochanters brownish-yellow; mesopleurum except prepectus and mesosternum, base of hind wing, scutellum, metascutellum, metapleurum, propodeum except basad of basal carina, extreme base of first abdominal tergite, fore femur, fore tibia, mid femur, hind coxa and hind femur orange; tarsal segments except fifth segments of all legs, mid tibia and hind tibia orange with brownish tinge; fifth tarsal segment of all legs, wing veins, hind trochanters and ovipositor sheath dark brown; ovipositor deep red; wings hyaline.

\section{Male}

Similar to female but more polished and slender; pronotum largely polished with few short rugae in middle groove, pronotal collar and upper margin with faint punctures; mesopleurum smooth and shiny in upper half and mesosternum, few short transstriae along anterior margin of speculum.

Colour: Similar to female except following markings: antenna completely black; face, clypeus, malar space, mandible except at apex, temple, semicircular carina, orbital stripes on frons, pronotal collar broadly, tegula, subtegular ridge and apices of all abdominal tergites yellow; thorax largely dark orange except mesoscutum anteriorly and propodeum basad of basal carina black; apex of hind femur with a black mark; tarsi of all legs dark brown.

Host: Unknown.

Biology: Unknown.

Distribution: Delhi, Karnataka, Kerala, Maharashtra, Tamil Nadu and Uttar Pradesh. 